\title{
Fin Length and Total Length Relationships of Silky Shark Carcharhinus falciformis Landed at Tanjung Luar Fish Landing Port, West Nusa Tenggara, Indonesia
}

\author{
Selvia Oktaviyani*, Wanwan Kurniawan, and Fahmi \\ Research Center for Oceanography, Indonesian Institute of Sciences, 14430 Jalan Pasir Putih 1, \\ Indonesia
}

\begin{abstract}
Shark fins are a very valuable product for international trade. This study aims to obtain the equations describing the relationship between fin length and the total length of silky shark. Using the total length at sexual maturity $(\mathrm{Lm})$, the equation is then used to estimate the fin length associated with this Lm, which can then be included in the recommendation for international shark fin trades. Data collection was carried out from March 2018 to February 2019 at Tanjung Luar Fish Landing Port, West Nusa Tenggara. All data were collected from 2,837 individuals of silky sharks, consisting of 1,416 females and 1,421 males. The total length of silky shark ranges from 61 to $282 \mathrm{~cm}$ for females and $18-283 \mathrm{~cm}$ for males. The relationships of first dorsal fin length and total length is DFL=$2.0151+0.1243 \mathrm{TL}$ (both sexes). Furthermore, the relationships of pectoral fin length and total length were found to be PFL=-8.0098+0.2127 TL (both sexes). The first dorsal fin length and pectoral fin length at the time the silky shark sexually matures were $23 \mathrm{~cm}$ and $35 \mathrm{~cm}$, respectively. This fin-total length relationship can be used by the fisheries authority to determine the allowed minimum size of silky shark fins for export.
\end{abstract}

\section{Introduction}

Carcharhinus falciformis or silky shark is a pelagic fish species that inhabit oceanic waters, beyond the continental slope and coastal waters. They commonly live near the surface to a depth of $500 \mathrm{~m}[1,2]$. They are widespread throughout the world in tropical and subtropical waters, i.e. in the western Atlantic, eastern Atlantic, Indian Ocean, Western Pacific and in the Eastern Central Pacific [1].

The silky shark is one of the most common shark species in Indonesian waters and caught in large numbers, both as target and bycatch [3-5]. According to the Indonesian fisheries statistical data, the total catch of silky sharks reached 15.077 tons [6]. Furthermore [4], stated that most Indonesian fishers catch silky sharks using longlines and drift nets operated

\footnotetext{
* Corresponding author: selvia.oktaviyani@gmail.com
} 
offshore. This species is most commonly fished in seven Indonesian Fisheries Management Area (WPP), i.e. WPP 711, 572, 573, 713, 714, 716 and 717 [4].

Silky sharks are traded in both local and international markets. Almost all parts are traded, including fins, meat, cartilage, skin, teeth, and many other derivates products. However, fins are the most valuable product for international trade. In Indonesia, the shark fins are particularly served as expensive shark fin soup in Chinese Restaurant or exported to other countries [4]. [7, 8] stated that shark fins are consumed in East and Southeast Asia, such as China, Hong Kong, Taiwan, Singapore, Malaysia, Vietnam, Korea, and Japan. China, Hong Kong, and Vietnam are the largest importers of shark fins [9].

The population of silky shark was predicted to decline in all regions, as a result of overexploitation that was driven by international trade demand [10]. Consequently, it has been listed in CITES (Convention on International Trade in Endangered Species of Wild Fauna and Flora) Appendix II since 2016. This act implies that international trade of all silky shark commodities (including fins, other body parts, and derivates products) should be regulated by a management mechanism according to the CITES rules. To address this issue, the Indonesian Institute of Sciences (LIPI) as the Scientific Authority in Indonesia composed the NDF (Non-Detriment Findings) document for the silky shark. NDF is an instrument endorsed by CITES convention that is used as the basis for managing the fishery and international trade of species listed in CITES Appendix II. Silky sharks in Indonesian waters must be managed properly and the management authority has to fulfill all recommendations on the NDF document [11].

Unfortunately, there is still no recommendation to regulate the minimum of allowed fins length for international trade. Therefore, this study was conducted to know the relationship between fin length (dorsal fin and pectoral fin) and total length such that it can be used to estimate the fin length by the total length data. Using the total length at sexual maturity $(\mathrm{Lm})$, the equation is then used to estimate the fin length associated with this Lm and then the minimum fin length at which shark has matured sexually can be determined. This, in turn, can be added to the recommendation for management authority and as an effort to support the sustainable management of silky shark in Indonesia.

\section{Material and Methods}

This study was conducted through a daily catch data recording by an enumerator at Tanjung Luar Fish Landing Port, West Nusa Tenggara, Indonesia, from March 2018 until January 2019 (Fig. 1). Data collection included sex determination, measurement of total length (TL), first dorsal fin length (DFL), first dorsal fin height (DFH) and pectoral fin length (PFL). Total length was measured from the anterior tip of the snout to the posterior part of the caudal fin. First dorsal fin length and pectoral length were measured from the fin base to the tip of the fin, meanwhile for first dorsal fin height was measured from the fin base to the tip of the fin (Fig. 2). The total length and fin length were measured to the nearest centimeter using a $5 \mathrm{~m}$ meter roll.

The determination of sex was done visually, based on the presence/absence of clasper as a male reproductive organ. Sexual maturity of males is based on the clasper condition using the criteria given by [12 -13]:

a. Immature, juvenile: clasper undeveloped, not calcified, small and very soft.

b. Maturing, adolescent: clasper not fully calcified, moderate and still soft.

c. Mature, adult: clasper fully calcified, very large and hard.

The relationships of the fin length and total length, as well as first dorsal fin height and first dorsal fin length of silky shark, was obtained from linear regression with the following equation: 


$$
\begin{aligned}
\text { DFL } & =a+b \text { TL } \\
\text { PFL } & =c+d T L \\
\text { DFH } & =e+f \text { DFL }
\end{aligned}
$$

where TL is the total length, a, c and e are intercepts, b, $\mathrm{d}$ and $\mathrm{f}$ are slopes, DFL is first dorsal fin length, PFL is pectoral fin length and DFH is first dorsal fin height.

The size at sexual maturity was estimated using the equation:

$$
\log \operatorname{Lm}=-0.1246+0.9924+\log (\operatorname{Lmax})
$$

where Lm is the size at sexual maturity and Lmax is maximum length [14].

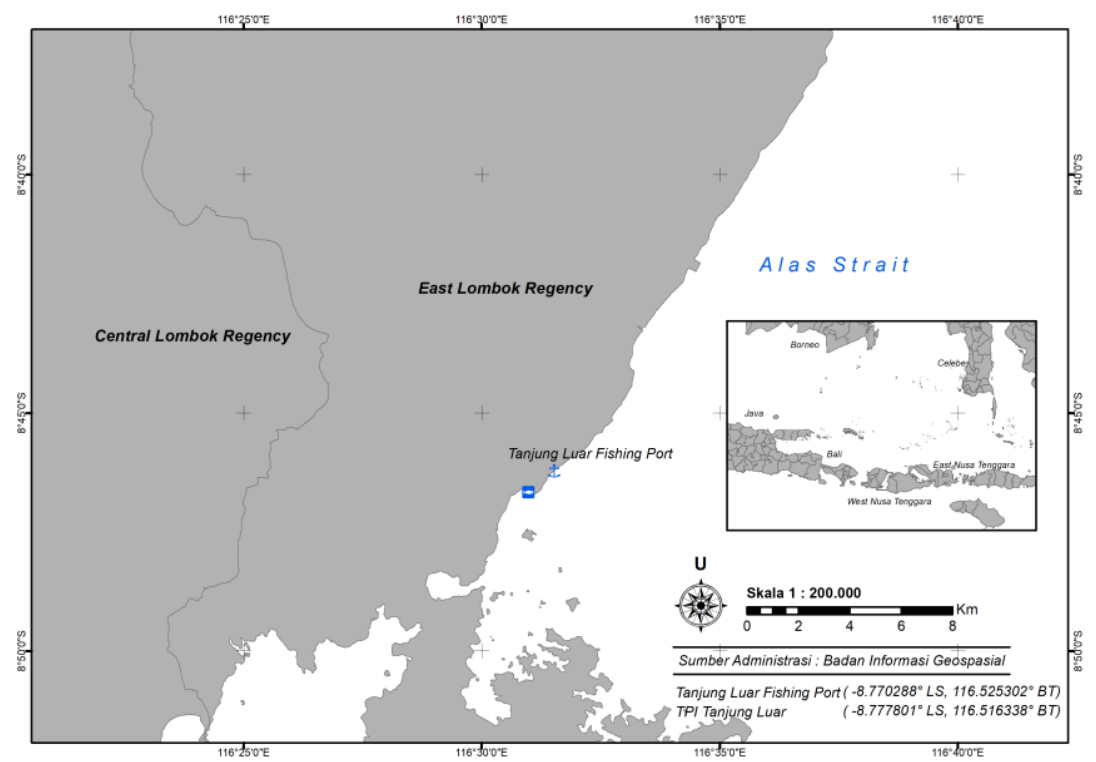

Fig. 1. Sampling site at Tanjung Luar Fishing Port, West Nusa Tenggara, Indonesia
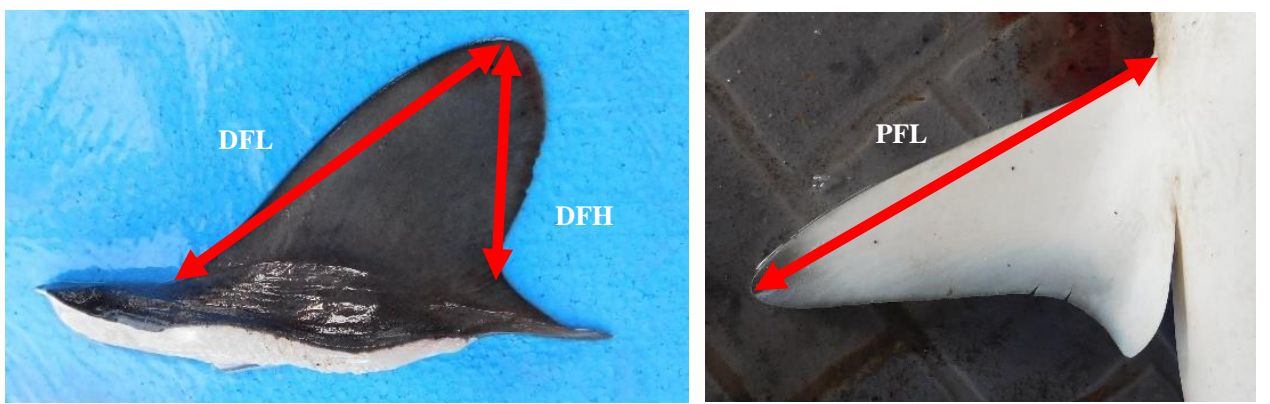

Fig. 2. Measurement of first dorsal fin length (DFL), first dorsal fin height (DFH) and pectoral fin length (PFL)

\section{Results}

Carcharhinus falciformis or silky shark has a medium size with an elongate and slender body, the snout is narrowly rounded and moderately long. The first dorsal fin is moderately high, 
its apex is rounded, its origin is behind the free rear tips of pectoral fins, pectoral fins are long and falcate, interdorsal ridge and precaudal pits are present (Fig. 3). Fishers at Tanjung Luar catch silky shark using drift longlines, surface longlines, gill nets, hand lines and purse seines in several waters including Alas Strait, Sawu Sea, Flores Sea, Northern Sumba, Southeast Sumbawa, Southeast Lombok, Bali Sea, and Makassar Strait.

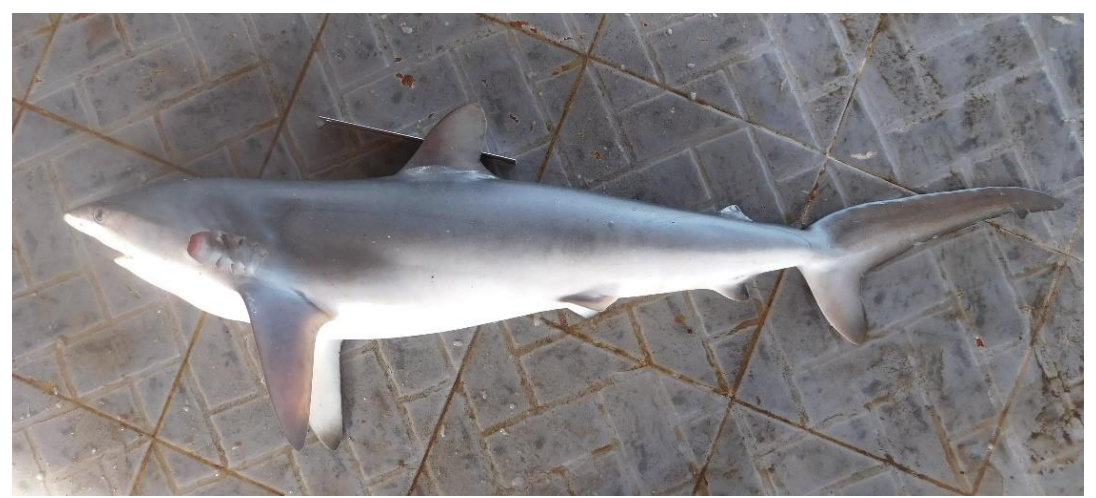

Fig. 3. Silky shark, Carcharhinus falciformis

During the study, a total of 2,837 silky sharks were recorded, consisting of 1,421 males and 1,416 females. The total length ranged between $65-283 \mathrm{~cm}$ for males and $61-282 \mathrm{~cm}$ for females. Silky sharks were predominantly caught at length between 187 and $204 \mathrm{~cm}$ TL (Fig. 4).

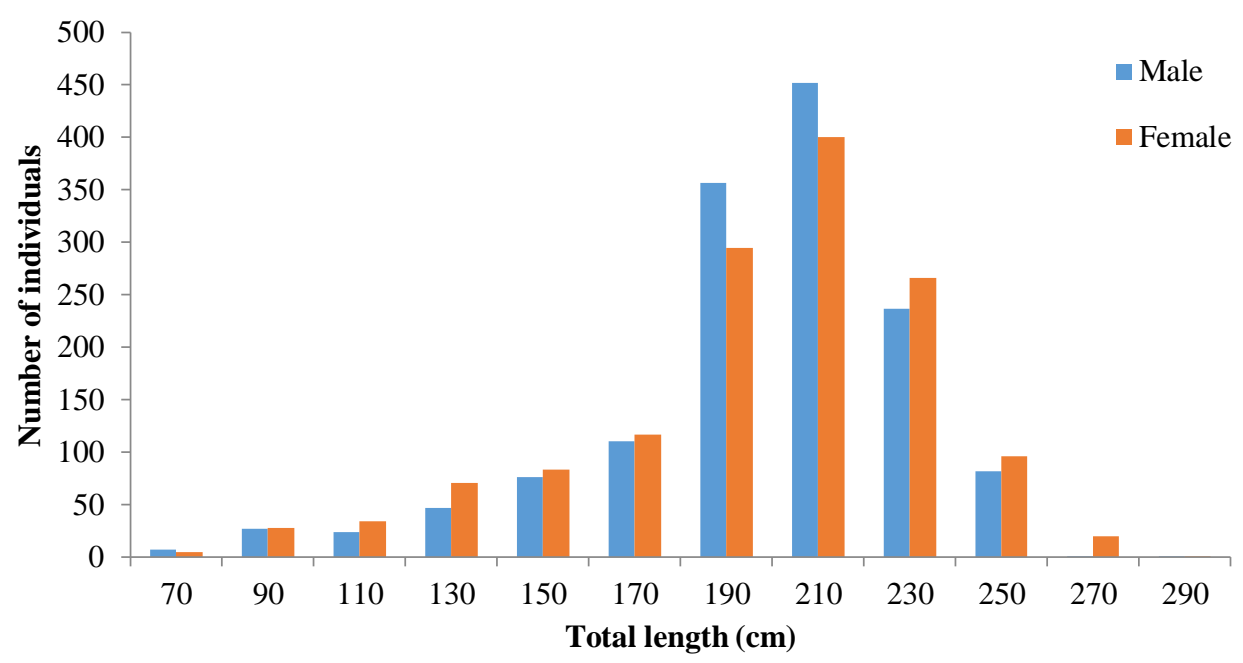

Fig. 4. Length frequency distribution of silky shark, Carcharhinus falciformis

Based on clasper condition, $51 \%$ or 725 males were mature individuals indicated by the long, fully calcified and hard claspers, with $11 \%$ and $38 \%$ were in maturing and immature stages, respectively (Fig. 5). Immature males ranged between 65 and $170 \mathrm{~cm}$ TL, maturing males had a length between 140 and $207 \mathrm{~cm}$ TL and mature males were found to be between 180 and $283 \mathrm{~cm}$ TL. 


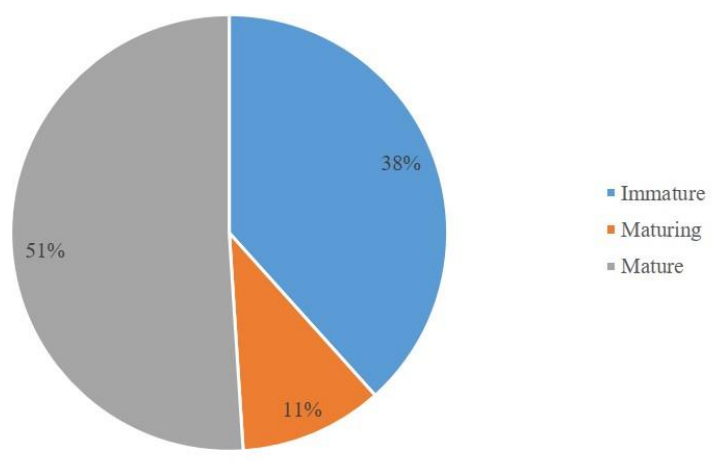

Fig. 5. Percentage of maturity stages for male Carcharhinus falciformis

a

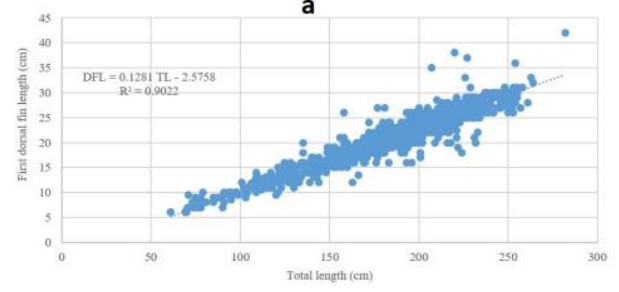

b

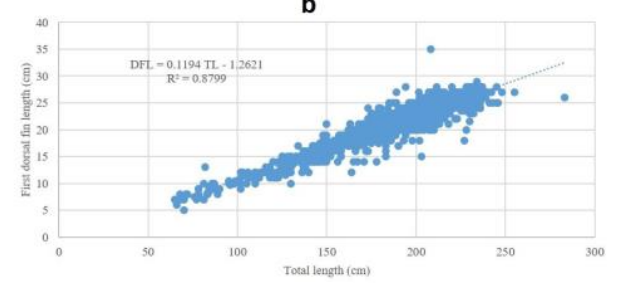

c

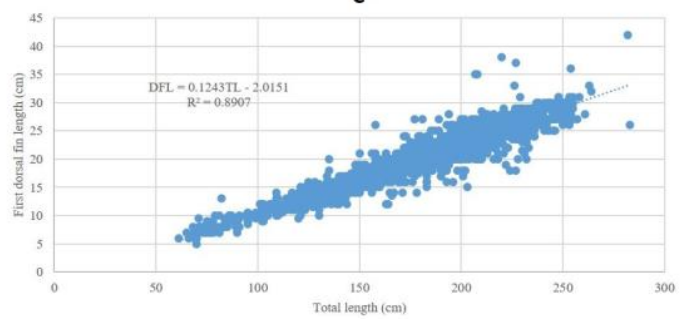

Fig. 6. Relationship of dorsal fin length and total length for female (a), male (b) and both sexes (c)

The relationships of first dorsal fin length and total length were DFL=-2.5758+0.1281 TL (females, Fig. 6a), DFL=-1.2621+0.1194 TL (males, Fig. 6b) and DFL=-2.0151+0.1243 TL (both sexes, Fig. 6c). Furthermore, the relationships between first dorsal fin height and first dorsal fin length were DFH=0.5910+0.7076 DFL (females, Fig. 7a). DFH=0.3403+0.7197 DFL (males, Fig. 7b) and DFH=0.4875+0.7126 DFL (both sexes, Fig. 7c). Meanwhile, pectoral fin length and total length are PFL=-9.2787+0.2217 TL (females, Fig. 8a), PFL=6.2915+0.2013 TL (males, Fig. 8b) and PFL=-8.0098+0.2127 TL (both sexes, Fig. 8c). 

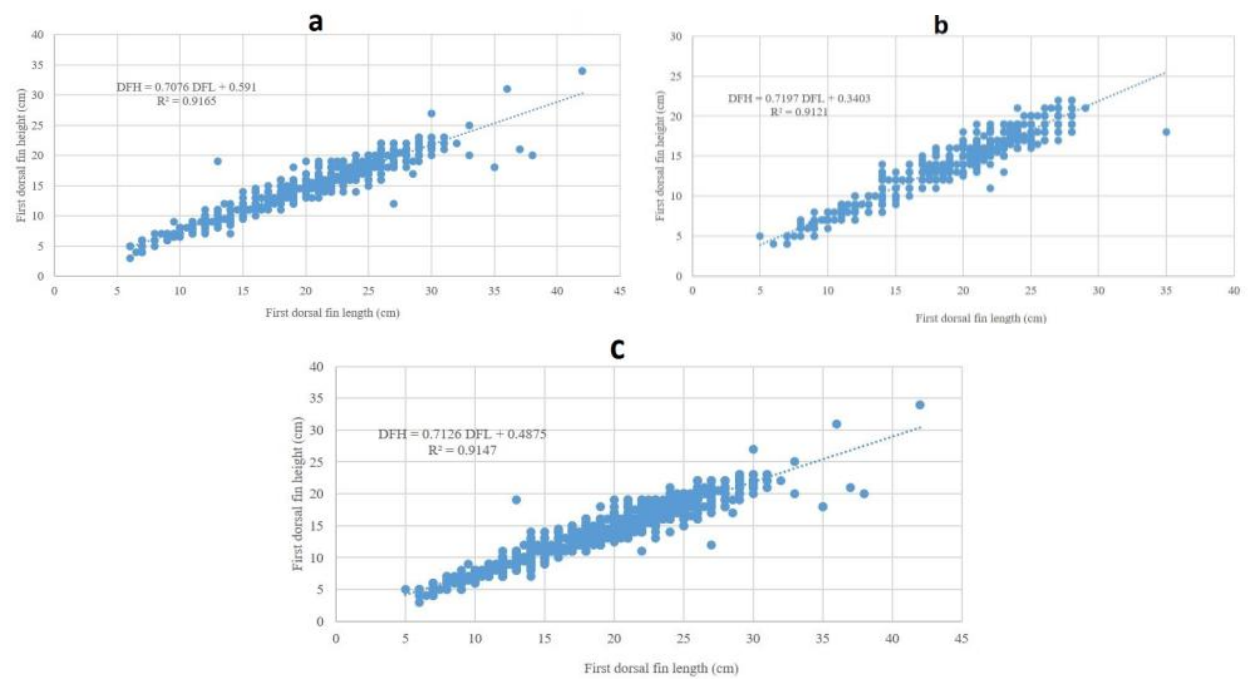

Fig. 7. Relationship of first dorsal fin height and first dorsal fin length for female (a), male (b) and both sexes (c)
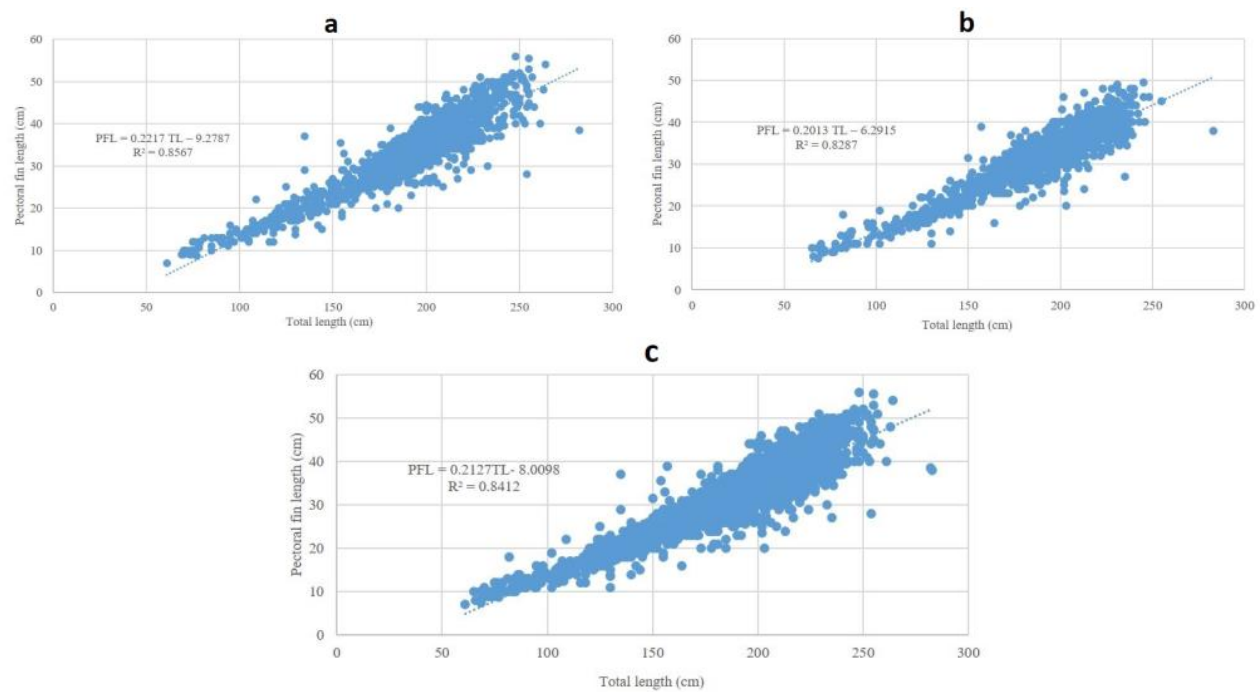

Fig. 8. Relationship of pectoral fin length and total length for female (a), male (b) and both sexes (c)

Based on the equation developed by [14], we estimated that silky sharks mature at size $203 \mathrm{~cm}$ TL (for both sexes). The mature silky shark was suggested to have the first dorsal and pectoral fin length at 23 and $35 \mathrm{~cm}$, respectively. Meanwhile, for first dorsal fin height is $17 \mathrm{~cm}$ (when DFL $23 \mathrm{~cm}$ ). Those values were obtained from the relationships between fin length and total length where total length at sexual maturity (Lm) was used.

\section{Discussion}

The maximum total length obtained was less than the one predicted by [1], i.e. $350 \mathrm{~cm}$. [15] recorded the total length of silky shark landed at Tanjung Luar Fish Landing Port ranged between $65-300 \mathrm{~cm}$. Meanwhile, the result of another study covering a fish landing site in Muncar, East Java found the total length from 88 to $318 \mathrm{~cm}$ [16]. The majority of silky sharks 
in the Indian Ocean were caught in total length between 181 and $190 \mathrm{~cm}$ [17]. This difference is allegedly due to the total number of sample size and exploitation rate. Tanjung Luar fishers targeted sharks as their catches, including silky sharks. [18] stated that this species contributed to more than $40 \%$ of the total shark catch in the Eastern Indian Ocean.

The size at sexual maturity $(\mathrm{Lm})$ found in this study was smaller than the ones estimated by [19-23]. Our estimated ratio between $\mathrm{Lm}$ and the maximum total length (Lm/Lmax ratio) was 0.72 . This ratio was within the range of the $\mathrm{Lm} / \mathrm{Lmax}$ ratio in the study of [24] who found the ratio was between 0.6 and 0.9 . The variations in $\mathrm{Lm}$ can be caused by many factors, such as environmental conditions, fishing pressure, biological characteristics and so on.

Around $35 \%$ of the total individuals collected were mature individuals. It means that $65 \%$ or 1,873 individuals were caught at a size smaller than Lm or in other words, fishers caught more immature or sub-adult silky sharks. This condition is not good for silky shark fishery in this area because silky sharks will not have the opportunity to grow up and reproduce. The size at sexual maturity $(\mathrm{Lm})$ can be used as the minimum length of sharks that can be caught by fishers. At least, they already spawned once to maintain its regeneration process.

In order to achieve a sustainable fishery of silky shark, we proposed to set the minimum size of fin products for international trade (export), i.e 23 and $35 \mathrm{~cm}$ for the first dorsal and pectoral length respectively, or $17 \mathrm{~cm}$ for first dorsal height. Hence, all fins with size less than those values are regarded as derived from immature sharks. The implementation of this recommendation needs to be followed up by the regulation of capture size restrictions. Through this rule, the number catches of juvenile sharks will decrease and there will be no more small-sized shark fins trading. Moreover, the management tools that are related to supervision and law enforcement need to be improved to prevent the international illegal trades

The minimum fin length of silky shark for international trade is proposed to be $23 \mathrm{~cm}$ for first dorsal fin and $35 \mathrm{~cm}$ for pectoral fin or $17 \mathrm{~cm}$ for first dorsal fin height. Restriction on fin size can be added in the recommendation for management authority. This recommendation must be supported with the other regulations, for instance, catch regulation, improving monitoring and law enforcement.

The author wishes to acknowledge the financial support provided by Riset Prioritas LIPI-COREMAP CTI the fiscal year 2018 and 2019. We also thank Galih Rakasiwi as an enumerator in Tanjung Luar Fish Landing Port, West Nusa Tenggara, Indonesia.

\section{References}

1. L. J. V. Compagno, V. H. Niem. Carcharhinidae in the Living Marine Resources of the Western Central Pacific Volume 2 Cephalopods, Crustaceans, Holothurians and Sharks (FAO, Rome, 1998)

2. W. T. White, P. R. Last, J. D. Stevens, G. K. Yearsley, Fahmi, Dharmadi. Economically important sharks and rays of Indonesia. (ACIAR, Canberra, 2006)

3. S. J. M. Blaber, C. M. Dichmont, W. White, R. Buckworth, L. Sadiyah, B. Iskandar, S. Nurhakim, R. Pillans, R. Andamari, Dharmadi, Fahmi. Rev. Fish Bio. And Fisheries 19, 367 (2009)

4. Fahmi, Dharmadi. A Review of the Status of Shark Fisheries and Shark Conservation in Indonesia. (Ministry of Marine Affairs and Fisheries, Jakarta, 2013)

5. Fahmi, Dharmadi. Afr. J. Mar. Sci 37, 259 (2015)

6. Directorate General of Capture Fisheries. Statistik Perikanan Tangkap Indonesia (Ministry of Marine Affairs and Fisheries, Jakarta, 2016) 
7. I. M. Zainudin. Pengelolaan Perikanan Hiu Berbasis ekosistem di Indonesia (University of Indonesia, Depok, 2011)

8. L. J. Marshall, M. Barone. Shark Fin Guide (FAO, Rome, 2016)

9. F. Dent, S. Clarke. State of the global market for shark proucts (FAO, Rome, 2015)

10. Convention on International Trade in Endangered Species of Wild Fauna and Flora. Consideration of Proposal for Amendment of Appendices I and II (2016)

11. Indonesian Institute of Sciences. Non Detriment Findings for Silky Shark Carcharhinus falciformis (2018)

12. H. L. Pratt. Copeia 3, 719 (1988)

13. M. F. W. Stehmann. Arch. Fishery and Mar. Res. 50, 23 (2002)

14. Binohlan C, R. Froese. J. Appl. Ichthyol 25, 611 (2009)

15. U. Chodrijah, I. Jatmiko, A.A. Sentoda. BAWAL 9, 175 (2017)

16. D. Adrian, R. R. Yuneni. Prosiding Simposium Hiu dan Pari di Indonesia (2015)

17. Dharmadi, Fahmi, M. Adrim. Jurnal Penelitian Perikanan Indonesia 13, 243 (2007)

18. Fahmi and dharmadi, 2015

19. S. Branstetter. Environ. Bio. Fishes. 19, 161 (1987)

20. R. Bonfil, R. Mena, D. De Anda. NOAA Tech. Rep 115, 73 (1993)

21. Fahmi, K. Sumadhiharga. Mar. Res. Ind 32, 7 (2007)

22. S. J. Joung, C. T. Chen, H. H. Lee, K. M. Liu. Fisheries Res. 90, 78 (2008)

23. N. G. Hall, C. Bartron, W. T. White, Dharmadi, I. C.Potter. J. Fish Bio. 80, 1320 (2012)

24. M. J. Holden, D. F. S. Raitt. Manual of fisheries science part 2-methods of resource investigation and their application. (FAO, Rome, 1974) 